\title{
Chain-Growth SuFEx Polycondensation: Molecular Weight Control and Synthesis of Degradable Polysulfates
}

\author{
Hyunseok Kim, Jiayu Zhao², Jinhye Bae², Liana M. Klivansky², Eric Dailing ${ }^{3}$, Yi Liu ${ }^{3}$, John R. Cap- \\ piello $^{1}, \mathrm{~K}$. Barry Sharpless ${ }^{1 *}$, and Peng $\mathrm{Wu}^{4 *}$ \\ ${ }^{1}$ Department of Chemistry, The Scripps Research Institute, La Jolla, California 92037, USA. \\ ${ }^{2}$ Department of NanoEngineering, University of California San Diego, La Jolla, CA 92093, USA. \\ ${ }^{3}$ The Molecular Foundry, Lawrence Berkeley National Laboratory, Berkeley, California 94720, USA. \\ ${ }^{4}$ Department of Molecular Medicine, The Scripps Research Institute, La Jolla, California 92037, USA.
}

\begin{abstract}
Sulfur (VI) fluoride exchange (SuFEx) click chemistry has offered a facile and reliable approach to produce polysulfates and polysulfonates. However, the current SuFEx polymerization methods lack precise control of target molecular weight and dispersity. Herein, we report the first chain-growth SuFEx polycondensation process by exploiting unique reactivity and selectivity of S-F bonds under SuFEx catalysis. Given the higher reactivity of iminosulfur oxydifluoride versus fluorosulfate, the chain-growth SuFEx polycondensation is realized by using an iminosulfur oxydifluoride-containing compound as the reactive chain initiator and deactivated AB-type aryl silyl ether-fluorosulfates bearing an electron-withdrawing group as monomers. When DBU was utilized as the polymerization catalyst, precise control over polymer molecular weight and polydispersity are achieved. The resulting polymers possess great thermal stability but are easily degradable under mild acidic and basic conditions.
\end{abstract}

\section{INTRODUCTION}

Since the modern concept of polymer was introduced by Staudinger in 1920s, ${ }^{1,2}$ many polymers and polymerization methods have been developed to meet the needs of diverse applications. There are two main streams of polymerization approaches, namely, step-growth and chain-growth polymerization. In early days, Carothers established step-growth polymerization (polycondensation) $)^{3,4}$ and led an aggressive expansion of synthetic polymers based on organic reactions. ${ }^{5,6}$ However, the molecular weight of polymers is difficult to control in a stepgrowth polymerization process since the coupling occurs between monomers and oligomeric intermediates without any selectivity. In other words, step-growth polymerization lacks selectivity between initiation and propagation process, leading to broad molecular weight distribution.

In this respect, 'chain-growth polycondensation' has attracted much attention from the polymer community. Since chain-growth polycondensation of polyamides ${ }^{7-9}$ developed by Yokozawa in 2000, various polymers such as polyethers, ${ }^{10-12}$ polyesters, ${ }^{13}$ polyethersulfones, ${ }^{14}$ and polythiophenes ${ }^{15}$ have been synthesized in a controlled manner. However, most of these resulted in oligomers, with the molecular weights below $10.0 \mathrm{k}$ despite their controlled manner. ${ }^{16-19}$ Recently, many enhanced examples are under way producing polyamides, ${ }^{20}$ polythiophene, ${ }^{21}$ poly(p-phenylene) ${ }^{22}$ graphene nanoribbons, ${ }^{23}$ as well as supramolecular polymers. ${ }^{24}$

An efficient coupling reaction is crucial for successful polymerization to produce well-defined and high molecular weight polymers. We and others have explored the benefits of the best click chemistry reactions in polymer synthesis, such reactions enable complete conversion along with unique orthogonal reactivity toward various functional groups. CuAAC (Cucatalyzed azide alkyne cycloaddition), a prototype of "click" chemistry which creates 1,4-triazole connections, has served with great reliability to emplace stable, covalent triazole attachment points into various functional polymers ${ }^{25}$ and materials ${ }^{26-}$ ${ }^{28}$ with high regioregularity. Moreover, complex structures ${ }^{29-31}$ and higher architectures such as graft and dendronized polymers ${ }^{32}$ were also successfully synthesized by using its advanced version (Cu-catalyzed multicomponent polymerization). Most of the examples afforded diverse step-growth polymers, while there are a few reports of chain-growth type CuAAC polymerization by holding $\mathrm{Cu}$ catalyst at the end of growing chain. ${ }^{33,34}$

With another recent click-caliber reaction, SuFEx [Sulfur (VI) Fluoride Exchange], it is now possible to create stable sulfate and sulfonate links with great ease and reliability. ${ }^{35,36}$ Via this approach, we have synthesized polysulfates and polysulfonates, ${ }^{37,38} 39$ in which AA and BB type monomers are used as building blocks (Fig. 1a) and the polymerization takes place between the fluorosulfate and the silyl ether-bearing monomers in the presence of the catalysts such as DBU (1,8-Diazabicyclo[5.4.0]undec-7-ene) and BEMP (2-tert-butylimino-2-diethylamino-1,3-dimethyl perhydro-1,3,2-diazaphosphorine). In terms of electronic properties, such a polymerization process can be depicted as a coupling reaction between an electrophilic monomer (fluorosulfates) and a nucleophilic counterpart (silyl ethers).

The intriguing observation was that the resulting polymers had somewhat moderate molecular weight distribution regardless of the step-growth design. ${ }^{40}$ To date, a controlled chaingrowth type polymerization enabled by SuFEx has yet to be developed. Here, we report the first chain-growth SuFEx polycondensation by modifying the electronic properties of SuFExable monomers to achieve precise control of the high molecular weight of polysulfates with narrow dispersity. Moreover, the resulting polymers were fully degradable under mild basic conditions. 
a Step-growth SUFEx polymerization (previous)
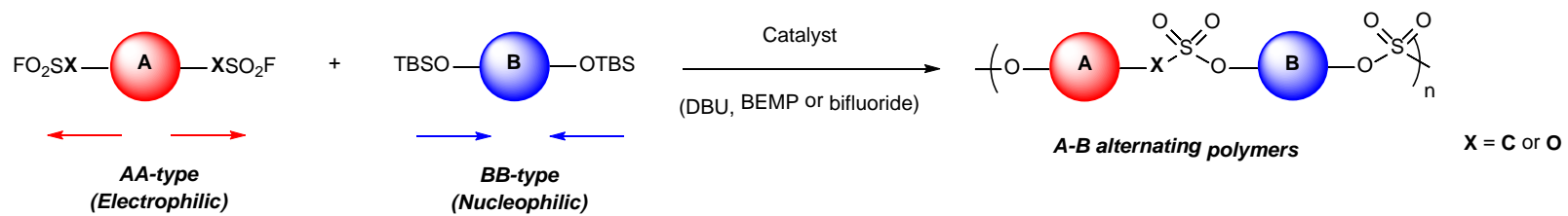

b Chain-growth SuFEx polycondensation (this work)
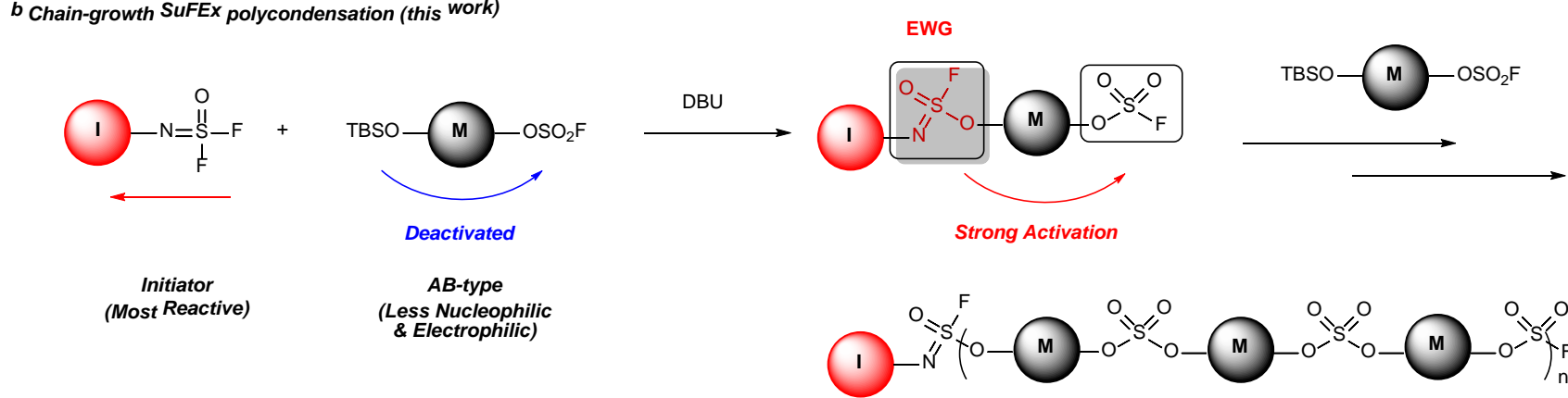

c Various AB-type monomers with different substituent
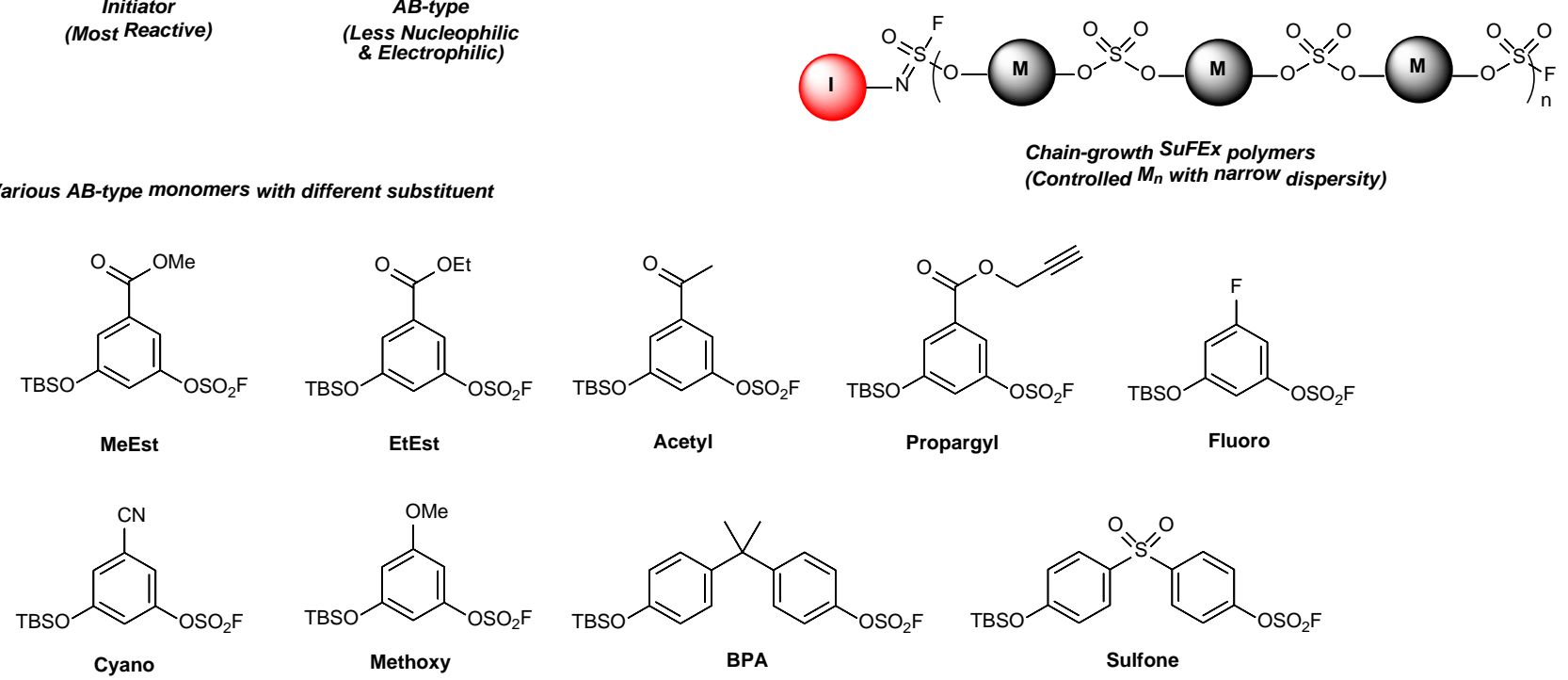

Figure 1. Schematic procedure of SuFEx polymerization. a, Conventional step-growth polycondensation. b, Chain-growth SuFEx Polycondensation. c, Various AB-type monomers with different electronics.

\section{RESULTS AND DISCUSSIONS}

Monomer design and evaluation of chain-growth polycondensation. To develop a SuFEx-based chain-growth polymerization requires: (1) A SuFExable initiator with significantly higher reactivities than monomeric building blocks; and (2) monomers that can undergo chain propagation.

Previously we discovered that the reactivity of various S-F bonds for SuFEx follows the order of $-\mathrm{N}=\mathrm{SOF}_{2}>>-\mathrm{SO}_{2} \mathrm{~F}>-$ $\mathrm{OSO}_{2} \mathrm{~F}^{41}$ Therefore, iminosulfur oxydifluoride seems to be a reasonable choice as the initiator for our proposed polymerization. To realize chain-growth polycondensation, AB-type monomers in a conjugated aromatic system that harbor a nucleophilic (-OTBS) group and an electrophilic group $\left(-\mathrm{OSO}_{2} \mathrm{~F}\right)$ will be employed. Importantly, the electronic properties of such a monomer can be fine-tuned such that the $-\mathrm{OSO}_{2} \mathrm{~F}$ group would not react with the -OTBS group within the same monomer but would react with the -OTBS group of another monomer to initiate the chain propagation once the polymerization is initiated. (Fig. 1b).

To test our hypothesis, a panel of AB-type monomers was synthesized as 1,3,5-trisubstituted monomers (Figure 1c). An electron-withdrawing group (EWG) or an electron-donating group (EDG) was introduced to the meta- or para-position of both electrophilic and nucleophilic site to tune the properties of the resulting monomers.

In the absence of any initiators, Methoxy and BPA monomers underwent self-condensation under our previously established SuFEx polymerization condition (20 mol\% of DBU). ${ }^{35}$ By contrast, under the same condition the monomers bearing EWG (MeEst, EtEst, Acetyl, and Fluoro) did not produce any polymers. Presumably, the presence of two EWGs (i.e. electronpoor alkyl substituent and fluorosulfate) inductively weakens the nucleophilicity of phenol, ${ }^{42,43}$ impeding effective SuFEx coupling. 
a
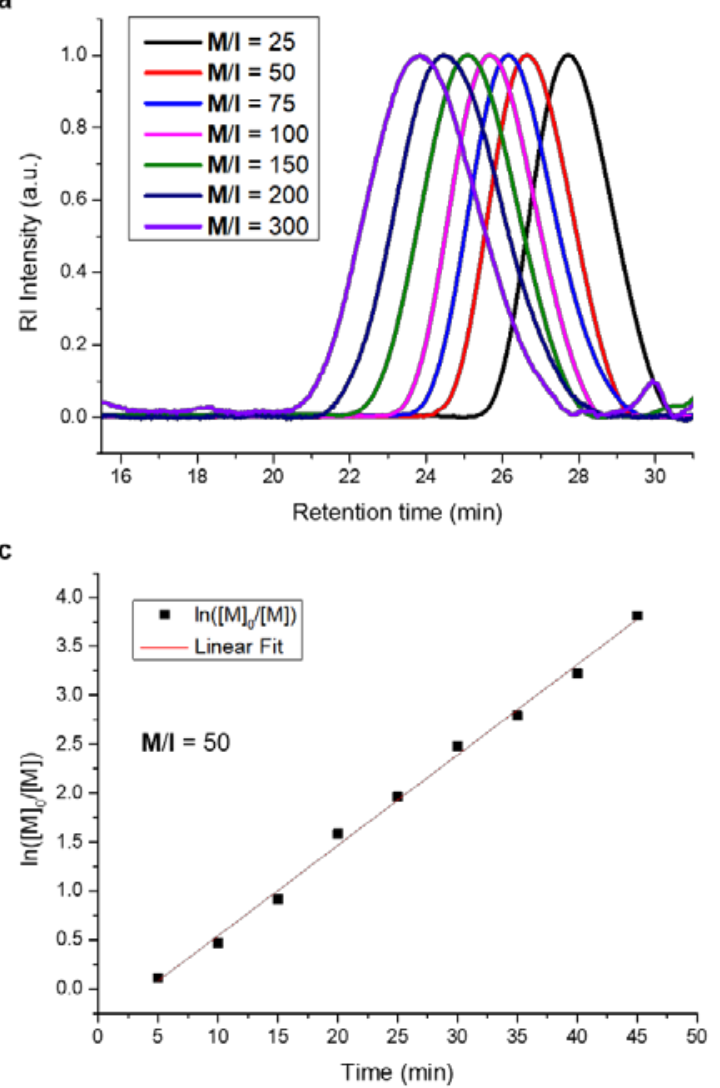

b

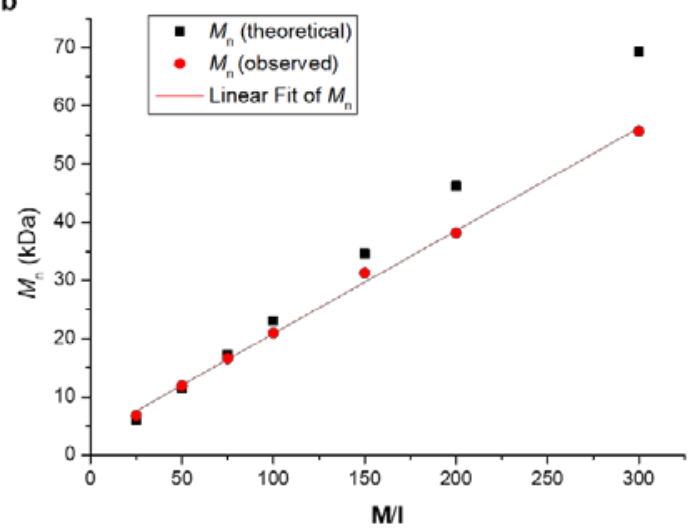

d

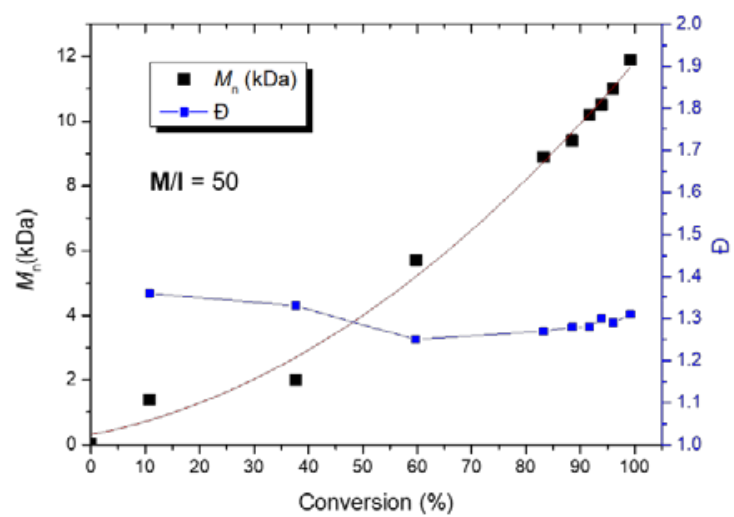

Figure 2. Molecular weight control of model polymerization with AB-type monomer (MeEst) and kinetic profiles. a, SEC traces of various monomer-to-initiator ratios (M/I). $\mathbf{b}, M_{\mathrm{n}} \mathrm{vs} \mathrm{M} / \mathrm{I}$ correlation. c, First-order kinetics of SuFEx polymerization at a fixed M/I ratio of 50. d, $M_{\mathrm{n}}$ vs conversion and $\oslash\left(M_{\mathrm{w}} / M_{\mathrm{n}}\right)$ vs conversion correlation at a fixed M/I ratio of 50 .

Interestingly, although electron-poor monomers did not produce self-condensation polymers, they successfully polymerized in the presence of an iminosulfur oxydifluoride $\left(-\mathrm{N}=\mathrm{SOF}_{2}\right)$ initiator (I) that also contains a 4-nitrobenzene group. A dry nitrile-based solvent, butyronitrile, rather than hygroscopic solvents such as DMF and NMP, ensured reproducibility of polymers at high temperatures (Supplementary Table 1, entries 713).

Kinetic studies and molecular weight control of a model polymerization. With a fixed monomer-to-initiator ratio (M/I) of 50, we then performed kinetic studies with a model polymerization of MeEst and the active initiator (I) to determine if a controlled chain-growth type polymerization is realized. After polymerization started, we observed a full conversion of the initiator into the chain-end taking place within $3 \mathrm{~min}$ (see ${ }^{1} \mathrm{H}$ and ${ }^{19}$ F NMR spectra in Supplementary Fig. 3). By analyzing aliquots taken at varying time intervals, we found that the consumption of MeEst exhibited first-order kinetics (Fig. 2c) and the molecular weight of the polymer increased in proportion to the conversion. Importantly, the molecular weight distribution maintained approximately 1.3 even at the overall conversion of $100 \%$ (Fig. 2d), indicating that this polymerization process does not follow a typical step-growth polymerization, which normally affords a broad distribution over 2.0 at the full conversion.

We further conducted a detailed survey of how molecular weight of MeEst polymers would be controlled at various M/I ratios (Table 1). As an optimized condition, the initiator to DBU ratio (I/cat.) was set to 1:1 to get reasonable kinetics of polymerization (Table 1, entry 2). When all monomers were consumed, the resulting polymers exhibited unimodal and low distributions as analyzed by size-exclusion chromatography (SEC) using polystyrene standards (Fig. 2a). Varying the ratios of monomer to initiator from 25 to 300 , the observed number-average molecular weight $\left(M_{\mathrm{n}}\right)$ of the polymers showed a linear increase (Fig. 2b). In addition, the degree of polymerization observed by the end-group analysis matched with feeding ratio (Supplementary Fig. 2). The dispersity $\left(D=M_{\mathrm{w}} / M_{\mathrm{n}}\right)$ of MeEst polymer remained at 1.3 until the $\mathrm{M} / \mathrm{I}$ ratio increased to 100 (Table 1, entries 1, 2, 5, and 6). However, when the $\mathrm{M} / \mathrm{I}$ reached 150, broadening was observed (Table 1, entry 7).

To make polymers with higher monomer-to-initiator ratios $(\mathrm{M} / \mathrm{I}=200$ and 300), a premixed stock solution of the initiator and DBU was applied to achieve a fast initiation in the presence of high concentrations of monomers (Supplementary Fig. 1). Under these conditions, the $D$ values of 1.44 and 1.55 were achieved for polymer products with the M/I of 200 and 300, respectively (Table 1 , entries 8 and 9). The observed broadening may be caused by the chain-end decomposition $\left(k_{t}\right)$ during the long reaction course and the slower propagation rate $\left(k_{\mathrm{p}}\right)$ by the excess of monomer that hinders proper coupling via DBU catalysis on the growing chain-end. 
Table 1. SuFEx polymerization of various AB-type monomers with active initiator (I). ${ }^{\text {a }}$

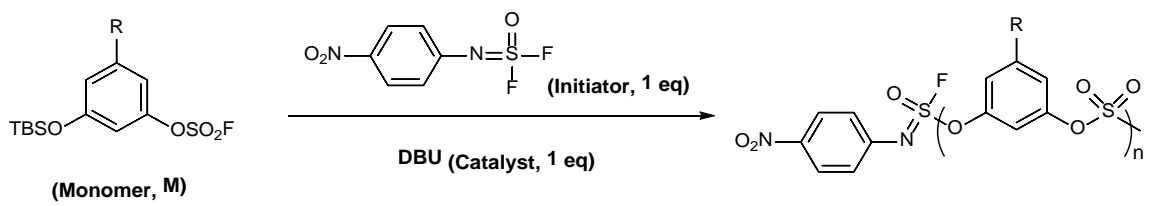

\begin{tabular}{|c|c|c|c|c|c|c|c|c|c|}
\hline Entry $^{\mathrm{a}}$ & Monomer & $\begin{array}{l}\text { Targeted DP } \\
\text { (Observed) }^{\mathrm{b}}\end{array}$ & [M]:[I]:[Cat.] & $\begin{array}{l}\text { Temp } \\
\left({ }^{\circ} \mathrm{C}\right)\end{array}$ & $\begin{array}{l}\text { Time } \\
\text { (h) }\end{array}$ & $\begin{array}{l}\text { Conv }^{\mathrm{C}} \\
(\%) \\
\end{array}$ & $M_{\mathrm{n}}$, theo ${ }^{\mathrm{d}}$ & $M_{\mathrm{n}, \mathrm{SEC}}{ }^{\mathrm{e}}$ & $\bigoplus^{\mathrm{e}}$ \\
\hline 1 & MeEst & 25 & $25: 1: 1$ & 90 & 0.3 & $99 \%$ & $6.0 \mathrm{k}$ & $6.8 \mathrm{k}$ & 1.27 \\
\hline 2 & MeEst & $50(52)$ & $50: 1: 1$ & 90 & 1 & $99 \%$ & $11.5 \mathrm{k}$ & $11.9 \mathrm{k}$ & 1.28 \\
\hline 3 & MeEst & 50 & $50: 1: 0.5$ & 90 & 3 & $99 \%$ & $11.5 \mathrm{k}$ & $12.8 \mathrm{k}$ & 1.30 \\
\hline 4 & MeEst & 50 & $50: 1: 0.2$ & 90 & 12 & $99 \%$ & $11.5 \mathrm{k}$ & $10.9 \mathrm{k}$ & 1.26 \\
\hline 5 & MeEst & 75 & $75: 1: 1$ & 90 & 2 & $99 \%$ & $17.3 \mathrm{k}$ & $16.6 \mathrm{k}$ & 1.37 \\
\hline 6 & MeEst & 100 & $100: 1: 1$ & 110 & 2 & $99 \%$ & $23.1 \mathrm{k}$ & $21.0 \mathrm{k}$ & 1.35 \\
\hline 7 & MeEst & 150 & $150: 1: 1$ & 110 & 8 & $99 \%$ & $34.6 \mathrm{k}$ & $31.3 \mathrm{k}$ & 1.45 \\
\hline $8^{f}$ & MeEst & 200 & $200: 1: 1$ & 110 & 48 & $>95 \%$ & $46.2 \mathrm{k}$ & $38.2 \mathrm{k}$ & 1.44 \\
\hline $9^{f}$ & MeEst & 300 & $300: 1: 1$ & 110 & 72 & $>95 \%$ & $69.3 \mathrm{k}$ & $55.7 \mathrm{k}$ & 1.55 \\
\hline 10 & EtEst & 50 (49) & $50: 1: 1$ & 90 & 1 & $99 \%$ & $12.4 \mathrm{k}$ & $12.2 \mathrm{k}$ & 1.29 \\
\hline 11 & EtEst & 100 & $100: 1: 1$ & 110 & 3 & $99 \%$ & $24.6 \mathrm{k}$ & $23.8 \mathrm{k}$ & 1.29 \\
\hline $12^{\mathrm{f}}$ & EtEst & 200 & $200: 1: 1$ & 110 & 48 & $99 \%$ & $49.0 \mathrm{k}$ & $39.5 \mathrm{k}$ & 1.39 \\
\hline $13^{f}$ & EtEst & 300 & $300: 1: 1$ & 110 & 72 & $99 \%$ & $73.5 \mathrm{k}$ & $66.6 \mathrm{k}$ & 1.46 \\
\hline 14 & Acetyl & $50(50)$ & $50: 1: 1$ & 90 & 1 & $99 \%$ & $10.7 \mathrm{k}$ & $13.2 \mathrm{k}$ & 1.27 \\
\hline 15 & Acetyl & 75 & $75: 1: 1$ & 90 & 2 & $99 \%$ & $16.1 \mathrm{k}$ & $16.8 \mathrm{k}$ & 1.25 \\
\hline 16 & Acetyl & 100 & $100: 1: 1$ & 90 & 2 & $99 \%$ & $21.5 \mathrm{k}$ & $20.4 \mathrm{k}$ & 1.29 \\
\hline 17 & Acetyl & 150 & $150: 1: 1$ & 90 & 8 & $99 \%$ & $32.2 \mathrm{k}$ & $28.3 \mathrm{k}$ & 1.31 \\
\hline $18^{\mathrm{f}}$ & Acetyl & 200 & $200: 1: 1$ & 90 & 48 & $>95 \%$ & $43.0 \mathrm{k}$ & $42.6 \mathrm{k}$ & 1.43 \\
\hline $19^{\mathrm{f}}$ & Acetyl & 300 & $300: 1: 1$ & 90 & 72 & $>95 \%$ & $64.5 \mathrm{k}$ & $53.0 \mathrm{k}$ & 1.52 \\
\hline 20 & Fluoro & $50(56)$ & $50: 1: 1$ & 90 & 1 & $99 \%$ & $9.5 \mathrm{k}$ & $9.7 \mathrm{k}$ & 1.31 \\
\hline 21 & Fluoro & 75 & $75: 1: 1$ & 90 & 2 & $99 \%$ & $14.3 \mathrm{k}$ & $14.0 \mathrm{k}$ & 1.37 \\
\hline 22 & Cyano & 50 & $50: 1: 1$ & 90 & 1 & $99 \%$ & $10.1 \mathrm{k}$ & insoluble & - \\
\hline 23 & Sulfone & 25 & $25: 1: 1$ & 90 & 4 & $99 \%$ & $8.0 \mathrm{k}$ & $17.6 \mathrm{k}$ & 1.31 \\
\hline 24 & Sulfone & $50(78)$ & $50: 1: 1$ & 90 & 12 & $99 \%$ & $15.6 \mathrm{k}$ & $31.0 \mathrm{k}$ & 1.18 \\
\hline
\end{tabular}

${ }^{\text {a }}$ Polymerization was conducted on $0.5 \mathrm{mmol}$ scale. ${ }^{\mathrm{b}}$ Degree of polymerization (DP) was determined by end-group analysis of ${ }^{1} \mathrm{H}$ or ${ }^{19} \mathrm{~F}$ NMR of polymer. ${ }^{\mathrm{c}}$ Conversions were determined by ${ }^{1} \mathrm{H}$ and ${ }^{19} \mathrm{~F}$ NMR of the crude mixture. ${ }^{\mathrm{d}} M_{\mathrm{n}, \text { theo }}=\mathrm{MW}(\mathrm{I})+\mathrm{M} / \mathrm{I}$ ratio $\times$ MW(M). ${ }^{\mathrm{e}}$ Determined by THF SEC calibrated using PS standards. $M_{\mathrm{n}}$ is given in $\mathrm{g} / \mathrm{mol} .{ }^{\mathrm{f}}$ Premixed stock solution (initiator + DBU) was applied to initiate polymerization.

Expansion of substrate scope with various AB-type monomers. Building upon the above results, we explored various AB-type monomers to expand the substrate scope for chaingrowth SuFEx polycondensation. The EtEst monomer, which has more hydrolytic resistance than MeEst, was examined for the polymerization. The molecular weights of the resulting polymers were in good agreement with calculated values at $\mathrm{M} / \mathrm{I}$ ratios of 50-300, showing $Ð$ range of 1.29-1.46 (Table 1, entries 10-13). Similar trends were observed when using a better $\pi$-accepting Acetyl monomer (Table 1, entries 14-17). Not surprisingly, the resulting polymers at high M/I ratios (200 and 300) also had slightly broader distributions (Table 1, entries 18 and 19).

The monomers with other electron-withdrawing groups polymerized as well, showing similar narrow dispersity (Table 1, entries 20-24). However, due to solubility issues, these monomers have a limitation in high $\mathrm{M} / \mathrm{I}$ ratios due to a lack of solubility. The Fluoro monomer could grow to M/I of 50 and 75, and the Sulfone derivative had M/I of 25 and 50 as a maximum feeding ratio. Unexpectedly, the Cyano derivative crashed out during the polymerization and produced an insoluble solid in various organic solvents (Table 1 , entries 22). Among these monomers, the most electron-deficient Sulfone analog showed the narrowest $Ð$ value (1.18), implying a well-controlled behavior in polymerization (Table 1, entry 24).
Chain-extension studies with combination of AB-type monomers. Next, we conducted chain-extension experiments with various EWG analogs to further verify that our SuFEx polymerization proceeded via the chain-growth mechanism (Fig. 3a). By reacting 25 or 75 eq of additional MeEst monomer with the $1^{\text {st }}$ block poly(MeEst $)_{25}\left(M_{\mathrm{n}}=6.8 \mathrm{k}, Ð=1.27\right)$ for homo-extension, we observed that the pristine polymer successfully elongated with clear shifts in SEC. Interestingly, the molecular weight of the initial polymer went down within $1 \mathrm{~h}$ upon the addition of the second monomer. It recovered to the original value shortly after and extended to the desired molecular weight after 3 hours (Fig. 3b). However, the observed $D$ of the extended polymer was found to be broader in comparison to the initial pristine polymer with $\mathrm{M} / \mathrm{I}=50$ (1.28 vs. 1.36 ) (Table 1 , entry 2 vs. Fig. 3d, entry 1 ). This trend was similar to $M / I=100$ vs. $\mathrm{M} / \mathrm{I}=25+75$ case (1.35 vs. 1.44 ) (Table 1 , entry 6 vs. Fig. 3d, entry 2).

Combining other electron-poor monomers (EtEst and Fluoro) with the $1^{\text {st }}$ block poly(MeEst $)_{50}\left(M_{\mathrm{n}}=11.9 \mathrm{k}, \emptyset=1.28\right)$ also showed high-molecular-weight shifts in SEC with relatively broad $Ð$ values (Fig. 3d entries 3, 4, and Supplementary Fig. 11). The broadness seemed to come from different propagation rates $\left(k_{\mathrm{p}}\right)$ of the monomers (Supplementary Fig. 6) and chain transfer reaction. Also, as observed in ${ }^{19} \mathrm{~F}$ NMR (Supplementary Fig. 4), the end-group signal of the first block $\left(-\mathrm{OSO}_{2}-\mathrm{F}\right)$ 
remained at a low level (12 \%) after precipitation in methanol. This result suggests that the propagating chain-end is very reactive but also hygroscopic. Of the catalysts that we studied, the chain-extension was only possible in the presence of DBU.

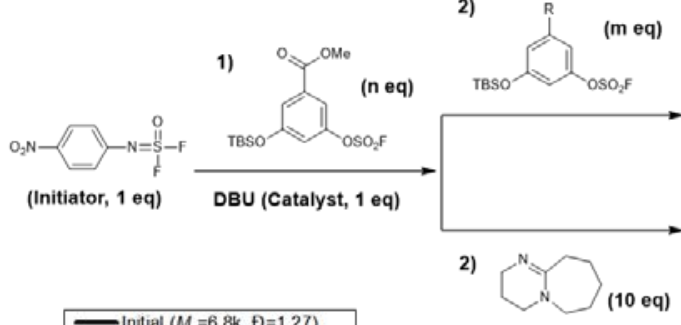

b

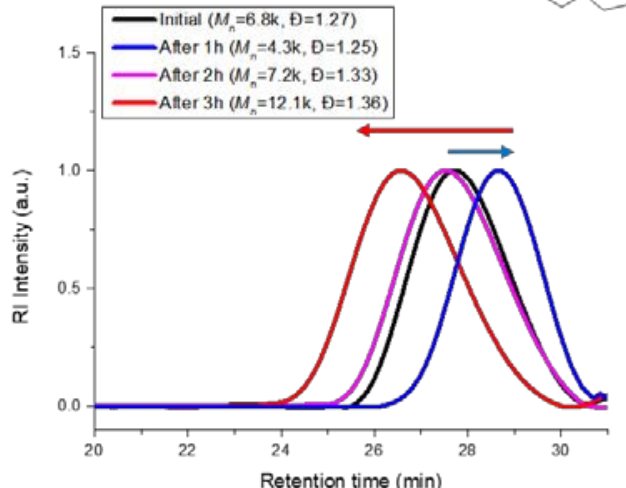

d

\begin{tabular}{|c|c|c|c|c|c|c|}
\hline Entry & $\mathbf{R}$ & $\begin{array}{c}n \\
\text { (obs) }\end{array}$ & $\begin{array}{c}m \\
\text { (obs) }\end{array}$ & $M_{n}$, theo & $M_{\mathrm{n}, \mathrm{sec}}$ & D \\
\hline 1 & MeEst & 25 & 25 & $11.5 \mathrm{k}$ & $12.1 \mathrm{k}$ & 1.36 \\
\hline 2 & MeEst & 25 & 75 & $23.1 \mathrm{k}$ & $19.9 \mathrm{k}$ & 1.44 \\
\hline 3 & EtEst & $\begin{array}{l}50 \\
(52)\end{array}$ & $\begin{array}{l}50 \\
(49)\end{array}$ & $23.9 \mathrm{k}$ & $20.6 \mathrm{k}$ & 1.43 \\
\hline 4 & $\begin{array}{l}\text { Fluoro } \\
\text { (block) }\end{array}$ & $\begin{array}{l}50 \\
(50)\end{array}$ & $\begin{array}{l}50 \\
(51)\end{array}$ & $21.2 \mathrm{k}$ & k & 1 \\
\hline 5 & $\begin{array}{c}\text { Fluoro } \\
\text { (random) }\end{array}$ & $\begin{array}{l}50 \\
(54) \\
\end{array}$ & $\begin{array}{l}50 \\
(50) \\
\end{array}$ & $1.2 \mathrm{k}$ & $19.5 \mathrm{k}$ & 1.60 \\
\hline
\end{tabular}

Other catalysts (e.g. BEMP and bifluoride) resulted in no chainextension of the initial polymers (Supplementary Fig. 11).
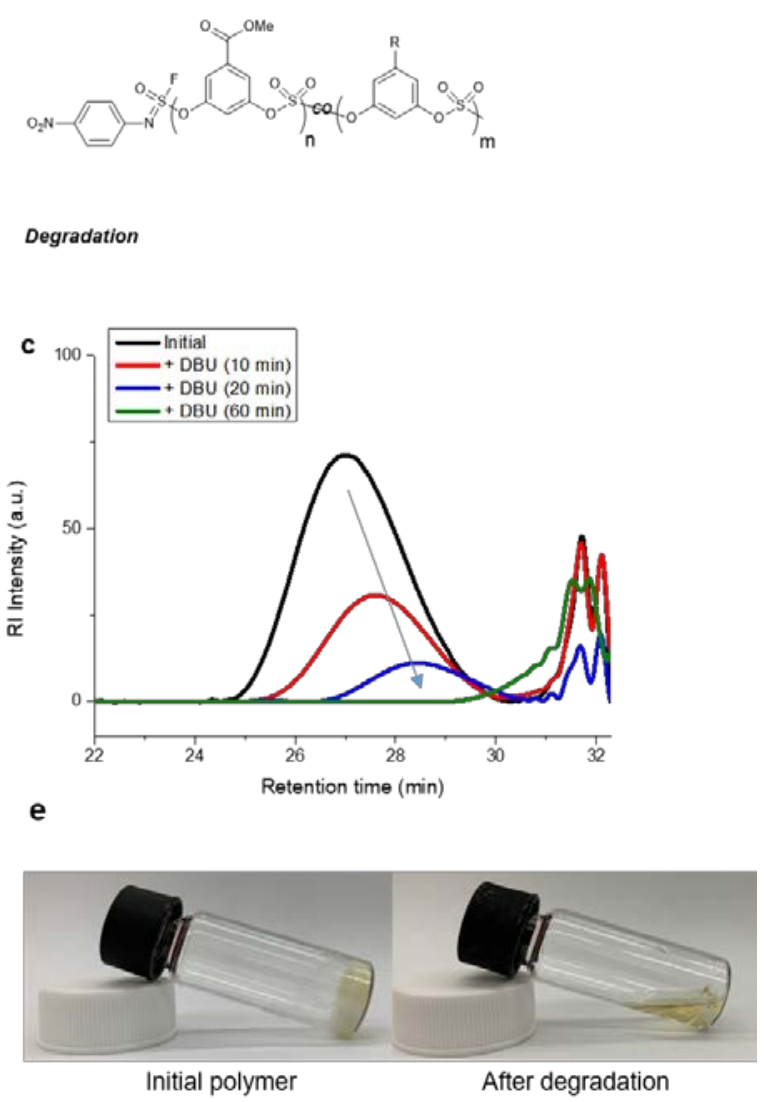

Figure 3. Chain extension (copolymerization) and degradation test of polysulfate. a, Schematic procedure of sequential addition

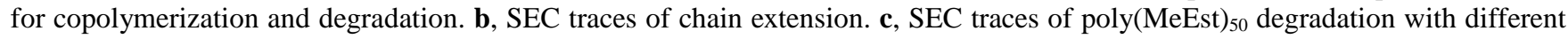
time scale. d, Various copolymerization results. e, Images of poly(MeEst) ${ }_{50}$ (Table 1, entry 2) before and after degradation.

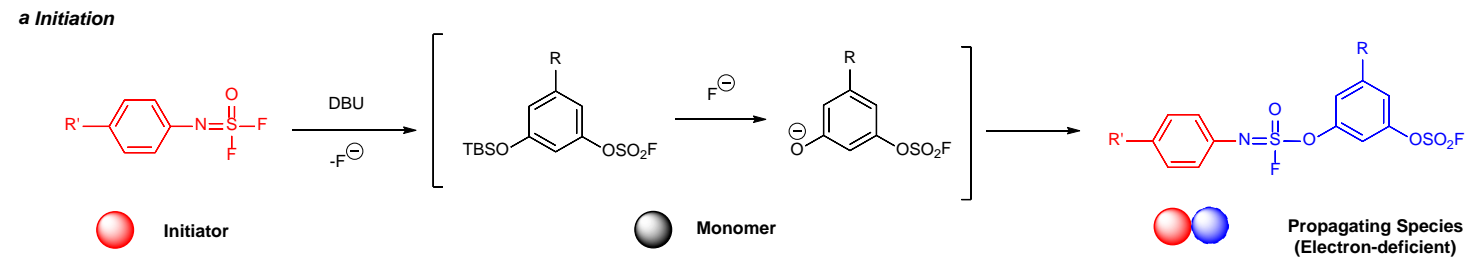

b Propagation

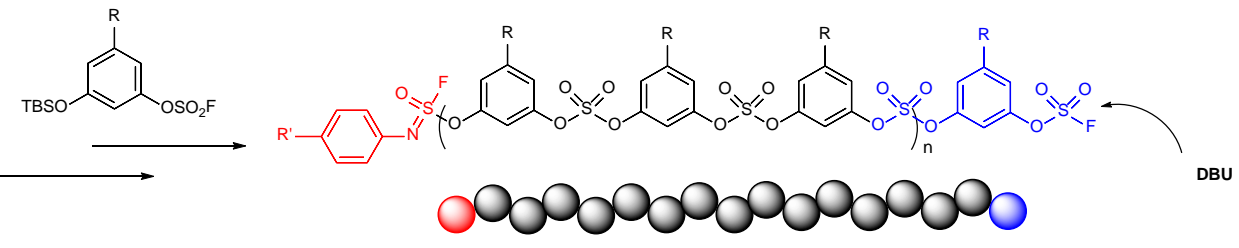

c Chain transfer
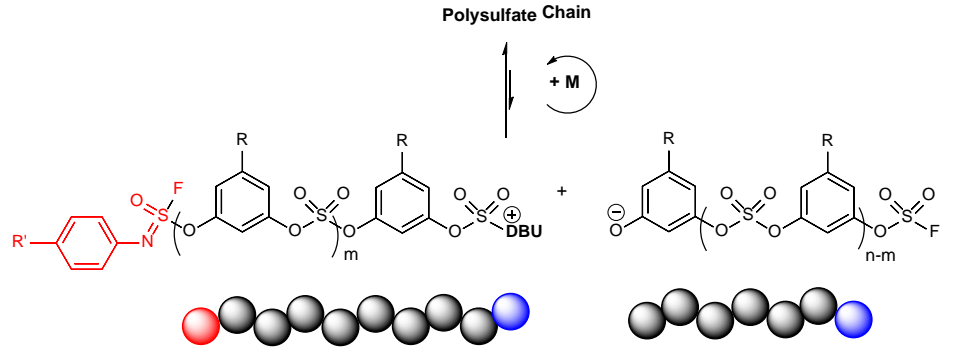
Figure 4. A proposed mechanism of chain-growth SuFEx polycondensation. a, Selective initiation of iminosulfur oxydifluoride to form propagating dimer. b, Propagation step by iterative SuFEx reaction. c, Chain transfer reaction through activation of sulfate linkage by DBU.

Structure analysis of polysulfates from block and random copolymerization. To identify the microstructure of the chainextended polymers, we also conducted thermal analysis of block and random copolymers from two distinct monomers. Since all the polysulfates except for the Fluoro homopolymer have an amorphous character without any melting transition or crystallization by differential scanning calorimetry (DSC), we chose MeEst and Fluoro monomers for the detailed analysis (Supplementary Table 5; cold crystallization temperature of Fluoro homopolymer: $69.2{ }^{\circ} \mathrm{C}$ and melting temperature: $\left.146.7^{\circ} \mathrm{C}\right)$. There were two glass transition temperatures $\left(\mathrm{T}_{\mathrm{g}}\right)$ appearing at $31{ }^{\circ} \mathrm{C}$ and $57{ }^{\circ} \mathrm{C}$ from the block copolymerization of MeEst and Fluoro (Fig. 3 entry 4). On the contrary, a random copolymer (Fig. 3 entry 5 ) showed a single $\mathrm{T}_{\mathrm{g}}$ at $30^{\circ} \mathrm{C}$. In addition, the intrinsic crystalline property of the Fluoro segment was expressed only in block copolymerization as $\mathrm{T}_{\mathrm{c}}$ of $114.4^{\circ} \mathrm{C}$ in the cooling cycle.

With the distinct patterns of the ${ }^{1} \mathrm{H}$ and ${ }^{19} \mathrm{~F}$ NMR signal (Supplementary Fig. 7), all of the results indicate that block and random copolymerization produced different microstructures. Nonetheless, the copolymerization runs in a block-like manner because of the chain transfer reaction. All these electron-deficient polysulfates exhibited great thermal stability as obtained by thermal gravimetric analysis (TGA). The decomposition temperatures $\left(\mathrm{T}_{\mathrm{d}}\right)$ of polysulfates ranged from $328.5{ }^{\circ} \mathrm{C}$ to $387.3^{\circ} \mathrm{C}$, and all the copolymers displayed a merged $\mathrm{T}_{\mathrm{d}}$ of each homopolymer.

Demonstration of proposed mechanism of chain-growth SuFEx polycondensation. The above results shed light on a possible mechanism of chain-growth SuFEx polycondensation. In the presence of an active initiator such as difluoride (I), DBU selectively activates the initiator over monomers (Fig. 4a, initiation). The strong affinity of the exchanging fluoride for silicon generates phenoxide, and the substituent effect of 1,3,5-functionalized monomer is retained. Even though AB-type monomers bearing an EWG are deactivated for SuFEx polymerization, one SuFEx coupling with initiator could change the electronics of the monomer to the polymerizable state (electron-deficient dimer). This can be considered as an intramolecular transformation of the substituent from an electron-rich group (OTBS) to an electron-poor group (-N=SOF-OAr). Once changed, it allows to induce a relay SuFEx coupling, leading to a continuous propagation in polymerization (Fig. 4b, favorable pathway).

However, because the generated backbone is composed of electron-poor sulfate bonds, the propagation contains a chain transfer reaction activated by DBU (Fig. 4c). The bending feature in the $M_{\mathrm{n}}$ vs. conversion plot implies that chain-transfer arises during the polymerization (Fig. 2d). Despite the chain transfer that can cause step-growth contaminants (see also Supplementary Fig. 5, MALDI-TOF), the substituent effect still influences propagation, and thus dispersity was not severely broadened like in typical step-growth polymerization.
As a chain-transfer reagent, we confirmed that a low loading of DBU proceeded to initiator-free polymerization in the case of $\mathrm{M} / \mathrm{I}=50$ and 100 . We expected that polymerization occurred by forming bis-sulfate dimers in equilibrium. However, the molecular weight of the initiator-free polymerization was not wellregulated, showing a higher molecular weight than the case of MeEst polymerization at $\mathrm{M} / \mathrm{I}=50$, and a much broader distribution than the case of MeEst polymerization at $\mathrm{M} / \mathrm{I}=100$ (Supplementary Fig. 9). Therefore, building predictable amounts of the polymerizable dimer and the fast initiation $\left(k_{\mathrm{i}}\right)$ from the high reactivity of initiators (I; $-\mathrm{NSOF}_{2}$ or $\mathrm{I}-1 ;-\mathrm{SO}_{2} \mathrm{~F}$ ) are essential for controlling $M_{\mathrm{n}}$ and $Ð$ value. Additionally, applying more active catalysts (e.g. BEMP and bifluoride) can give a different microstructure through activating the two fluorides of the initiator (Supplementary Fig. 10).

Degradability of polysulfate backbone and derived crosslinked gels. Degradable polymers are desirable for sustainability. ${ }^{44-47}$ Although stable covalent linkages in conventional polymers have contributed to the development of practical materials with high strength and resistance, ironically, their durability and non-recyclability due to the irreversible crosslinking, such as that found in thermosets, has become a major cause of plastic pollution nowadays. This emerging awareness has triggered a demand for degradability in polymeric materials.

To explore if our polysulfate polymers possess any degradability, we subjected the electron-deficient polysulfate [poly(MeEst) ${ }_{50}$ ] to various conditions (Supplementary Table 3). Because a previous study showed that polysulfonates can be degraded by DBU at an elevated temperature, ${ }^{48}$ we first tested the degradability of our polysulfates by incubating poly(MeEst) ${ }_{50}$ with DBU (10 mol\% in THF) at rt. In a few mins, the polymer changed from a solid to a liquid state (Fig. 3c and 3e) and was completely degraded within 1 hour. LC-MS analysis confirmed the presence of mono-sulfates, bis-sulfates, and trimer sulfates in the degraded solution (Supplementary Fig. 8). Notably, under the same condition, we did not observe the degradation of BPA polysulfate $^{35}$ (also see Supplementary Table 4). This result suggested that the electron-deficient substituents on the polymer backbone weakens the sulfate bond $\left(-\mathrm{SO}_{4}-\right)$ toward a nucleophilic base.

We then examined a few related catalysts such as DMAP (4Dimethylaminopyridine) and BTMG (2-tert-Butyl-1,1,3,3-tetramethylguanidine). However, as a relatively weak pyridyl base, DMAP only led to partial polymer degradation even after $24 \mathrm{~h}$ exposure with heating. Although BTMG has similar basicity to DBU, it only started to induce degradation at elevated temperatures (entry 7 and entry 9, Supplementary Table 3). Further studies conducted in various aqueous buffers revealed that this polymer was stable between $\mathrm{pH} 5$ to $\mathrm{pH} 7$ but sensitive toward mild acidic and basic conditions. ${ }^{49}$ Both aqueous ammonia and $0.5 \mathrm{M} \mathrm{KOH}$ solution could lead to its full degradation. 


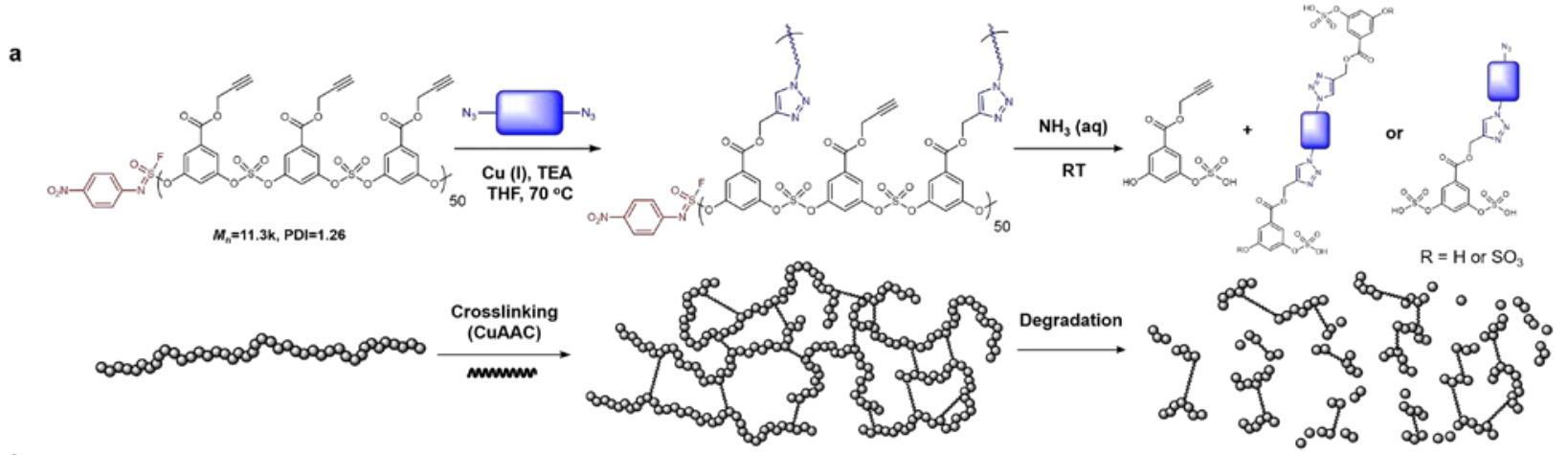

b
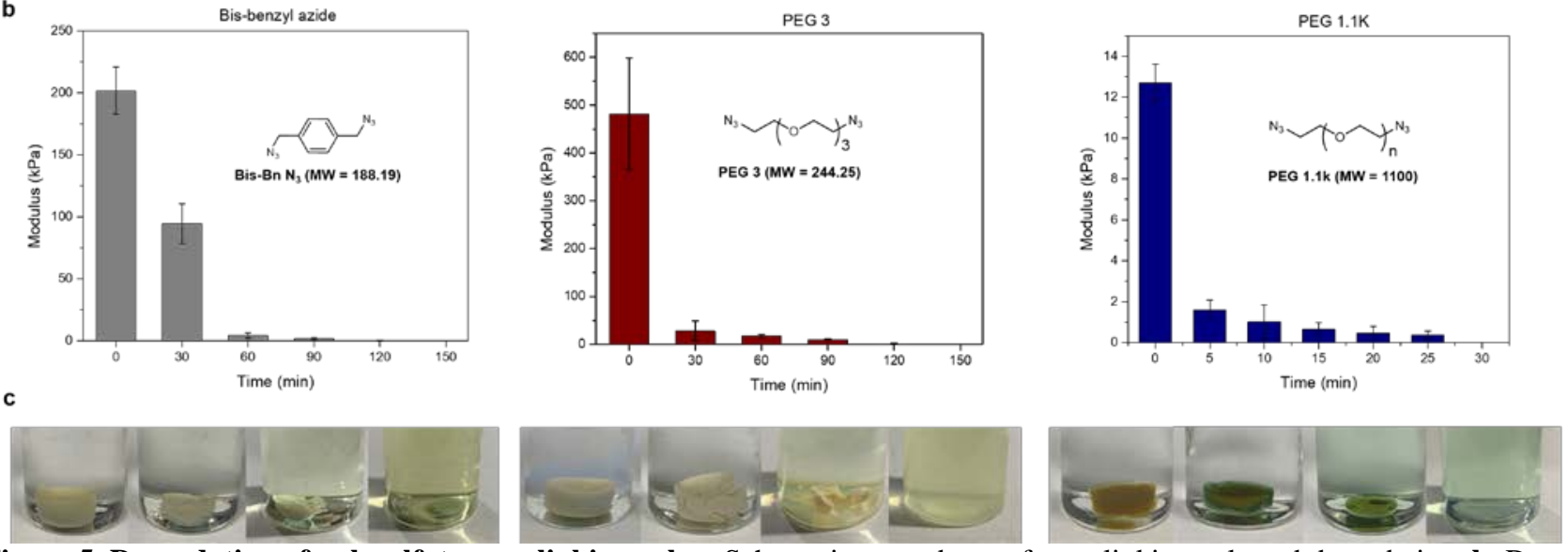

Figure 5. Degradation of polysulfate crosslinking gel. a, Schematic procedures of crosslinking gels and degradation. b, Degradation modulus in soaking aqueous ammonia. c, Images of degrading gels with different time interval (see section 16 in Supplementary Information for details).

With the properties of our polysulfate backbone characterized, we next investigated degradability of crosslinked gels formed by polysulfates. These gels, so called, thermosets are known to be difficult to break and hard to remold due to their permanent crosslinking resulting multiple 3D-network structures. Recently, many approaches to overcoming this issue have been reported by applying sensitive or reversible bonds toward various stimuli, such as acid, ${ }^{50}$ base,${ }^{51}$ anion, ${ }^{52,53}$ radical, ${ }^{54}$ and dynamic bonds. ${ }^{55,56}$

To construct crosslinked gels, we prepared a polymer with the polysulfate backbone decorated with propargyl side chains $(\mathrm{M} / \mathrm{I}=50)$. We then used CuAAC to induce the cross linking of the resulting polymer with different types of bis-azides to produce gel-like materials (Fig. 5a). We tracked the moduli of each gel by the nanoindentation technique. Among three different crosslinkers, the rigid bis-benzyl and short PEG linker formed relatively stiff gels, showing higher initial modulus (202 kPa for bis-benzyl azide and $482 \mathrm{kPa}$ for PEG 3, respectively). As the spacer became longer, e.g. $\mathrm{N}_{3} \mathrm{PEGxN}_{3} 1.1 \mathrm{k}$, a soft elastic gel was obtained with a lower Young's modulus (13 kPa) (Fig. 5b).

To determine the degradability of the above crosslinked gels, we placed them in aqueous ammonia solution at room temperature and checked their status. As the gels hydrolyzed (Fig. 5c), the solution gradually turned green by the chelation of ammonia with the trace amount of $\mathrm{Cu}$ species entrapped inside of the gels. The modulus of the rigid bis-benzyl azide gel fell by half within 30 minutes (202 kPa to $94 \mathrm{kPa}$ ) and the gel turned gummy after 1 hour. Because of the hydrophobic nature of the bis-benzyl spacer, a trace of the degraded residue remained as aggregates in aqueous solution, however, gels crosslinked via the watersoluble polyethylene glycol (PEG) units afforded a transparent

solution after degradation. Moreover, faster soaking and decomposition occurred when more hydrophilic spacers were used. For example, the gel crosslinked by the short PEG 3 spacer showed only severe cracking after 30 minutes (from 482 $\mathrm{kPa}$ to $28 \mathrm{kPa}$ ), whereas the more hydrophilic PEG $1.1 \mathrm{k}$ spacer showed a much faster decrease in modulus within 5 min (from $13 \mathrm{kPa}$ to $1.6 \mathrm{kPa}$ ), producing a clear solution after $25 \mathrm{~min}$ (see Supplementary CuAAC gel section for more information).

\section{CONCLUSION}

In summary, we have developed the first chain-growth SuFEx polycondensation by exploiting the high reactivity of iminosulfur oxydifluorides over fluorosulfates. Introducing a selective initiator and AB-type monomers was the key to achieve successful chain-growth SuFEx polycondensation. To maximize the electronic effect, monomers were designed with a nucleophile (silyl ether), an electrophile (fluorosulfate), and an additional EWG. The substituent effect of various electrondeficient AB-type monomers separates the reactivity of fluorosulfate $\left(-\mathrm{OSO}_{2} \mathrm{~F}\right)$ in the polymer chain-end and in the monomer, providing polysulfates with well-controlled molecular weight and narrow dispersity.

However, since this SuFEx polymerization adopts a chain transfer reaction, the sequential monomer addition results in a block-like structure and increasing the amounts of DBU causes the degradation of polymer. As the susceptibility of the sulfate bonds is dependent on the electronic environment, polymers and crosslinked gels bearing electron-withdrawing substituents can be fully degraded under basic conditions. These controllable and degradable features in polymerization pave the way for sustainable polysulfates with desired mechanical properties. 


\section{METHODS}

Procedure for the synthesis of the model polymer $(0.5 \mathrm{mmol}$ scale). To a flame-dried $4 \mathrm{~mL}$ vial equipped with a magnetic stirrer, AB-type monomer (M, 25-300 eq) - MeEst (154 uL, $d=1.184)$ and iminosulfur oxydifluoride initiator (I, $1 \mathrm{eq}, 0.37-4.44 \mathrm{mg}$ ) from stock solution was premixed with $500 \mathrm{uL}$ of butyronitrile (1 M to monomer, dried with activated $4 \AA$ molecular sieves). The vial was sealed with septum cap and placed at desired temperature $\left(90^{\circ} \mathrm{C}\right)$ for $5 \mathrm{~min}$. Then, catalyst from another batch of a stock solution (0.5 $\mathrm{M}$ of DBU in butyronitrile, 1 eq) was quickly injected to a reaction mixture as one-shot to initiate polymerization. For the high M/I of 200 and 300, a stock solution - premixed 1:1 mixture of initiator and DBU - was injected as one-shot to a pre-warmed reaction mixture to initiate polymerization. The polymerization underwent at desired temperature with stirring until the full consumption of monomer, and the mixture was precipitated into $\mathrm{MeOH}$ twice. The resulting polymer was dried under vacuum affording a white solid (for $\mathrm{M} / \mathrm{I}=50: M_{\mathrm{n}}=11.9 \mathrm{k}$ and $Ð=1.28,95 \%$ yield). The precipitated polymer was characterized by SEC, MALDI-TOF, and ${ }^{1} \mathrm{H}$, ${ }^{13} \mathrm{C},{ }^{19} \mathrm{~F}$ NMR. Full experimental details and characterization of compounds are given in the Supplementary Information.

\section{ACKNOWLEDGMENT}

The authors gratefully acknowledge financial support from the National Science Foundation (CHE-1610987 to KBS) and the NIH (R35GM139643 to PW). This work was also sponsored in part by the UC San Diego Materials Research Science and Engineering Center (UCSD MRSEC), supported by the National Science Foundation (Grant DMR-2011924). Part of the work was carried out as a user project at the Molecular Foundry, which was supported by the Office of Science, Office of Basic Energy Sciences, of the US Department of Energy under Contract No. DE-AC02-05CH11231.
We thank Jia Niu at Boston College for helpful discussions on this project.

\section{Author contributions}

K.B.S. and P.W. supervised the work. H.K. designed the experiments and performed the synthesis and characterization of the polymers. P.W. provided helpful suggestions on the project. J.Z. and J.B. collected and analyzed physical properties of gels. L.M.K., E.D., and Y.L. collected TGA and DSC data of all polymers and measured absolute molecular weight of polymers. H.K. wrote the manuscript. J.Z., J.B., J.R.C., P.W., and K.B.S. edited the manuscript.

\section{Additional information}

Supplementary information and chemical compound information are available in the online version of the paper. Reprints and permissions information is available online at www.nature.com/reprints. Publisher's note: Springer Nature remains neutral with regard to jurisdictional claims in published maps and institutional affiliations. Correspondence and requests for materials should be addressed to P.W. and K.B.S.

\section{Data availability statement}

The authors confirm that the data supporting the findings of this study are available within the article and its supplementary materials.

\section{Competing financial interests}

The authors declare no competing financial interests.

\section{REFERENCES}

1 Staudinger, H. Über polymerisation. Berichte der deutschen chemischen Gesellschaft (A and B Series) 53, 1073-1085 (1920).

2 Mülhaupt, R. Hermann Staudinger and the origin of macromolecular chemistry. Angewandte Chemie International Edition 43, 1054-1063 (2004).

3 Carothers, W. H. Studies on polymerization and ring formation. I. An introduction to the general theory of condensation polymers. Journal of the American Chemical Society 51, 2548-2559 (1929).

4 Carothers, W. H. Polymers and polyfunctionality. Transactions of the Faraday Society 32, 39-49 (1936).

$5 \quad$ Carothers, W. H. Polymerization. Chemical Reviews 8, 353-426 (1931).

6 Smith, J. K. \& Hounshell, D. A. Wallace H. Carothers and fundamental research at Du Pont. Science 229, 436-442 (1985).

7 Yokozawa, T., Asai, T., Sugi, R., Ishigooka, S. \& Hiraoka, S. Chain-growth polycondensation for nonbiological polyamides of defined architecture. Journal of the American Chemical Society 122, 8313-8314 (2000).

8 Ohishi, T., Sugi, R., Yokoyama, A. \& Yokozawa, T. Synthesis via Chain-Growth Condensation Polymerization and Gelating Properties of a Variety of Block Copolymers of Meta-and ParaSubstituted Aromatic Polyamides. Macromolecules 41, 9683-9691 (2008).

9 Ohta, Y., Kamijyo, Y., Fujii, S., Yokoyama, A. \& Yokozawa, T. Synthesis and Properties of a Variety of Well-Defined HyperbranchedN-Alkyl andN-H Polyamides by Chain-Growth Condensation Polymerization of AB2Monomers. Macromolecules 44, 5112-5122, doi:10.1021/ma200980t (2011). 
10 Yokozawa, T., Suzuki, Y. \& Hiraoka, S. Aromatic polyethers with low polydispersities from chain-growth polycondensation. Journal of the American Chemical Society 123, 9902-9903 (2001).

11 Suzuki, Y., Hiraoka, S., Yokoyama, A. \& Yokozawa, T. Chain-growth polycondensation for aromatic polyethers with low polydispersities: Living polymerization nature in polycondensation. Macromolecules 36, 4756-4765 (2003).

12 Ajioka, N., Suzuki, Y., Yokoyama, A. \& Yokozawa, T. Synthesis of well-defined polystyrene-baromatic polyether using an orthogonal initiator for atom transfer radical polymerization and chain-growth condensation polymerization. Macromolecules 40, 5294-5300 (2007).

13 Yokoyama, A., Iwashita, K.-i., Hirabayashi, K., Aiyama, K. \& Yokozawa, T. Investigation of aromatic polyester synthesis by the chain-growth polycondensation method. Macromolecules 36, 4328-4336 (2003).

14 Yokozawa, T., Taniguchi, T., Suzuki, Y. \& Yokoyama, A. Chain-growth polycondensation of monomer consisting of two aromatic rings: Synthesis of well-defined poly(ether sulfone) from 4fluoro-4?-hydroxydiphenyl sulfone. Journal of Polymer Science Part A: Polymer Chemistry 40, 3460-3464, doi:10.1002/pola.10429 (2002).

15 Yokoyama, A., Miyakoshi, R. \& Yokozawa, T. Chain-growth polymerization for poly (3hexylthiophene) with a defined molecular weight and a low polydispersity. Macromolecules 37, 1169-1171 (2004).

16 Yokozawa, T. \& Yokoyama, A. Chain-growth polycondensation: living polymerization nature in polycondensation and approach to condensation polymer architecture. Polymer journal 36, 65-83 (2004).

17 Yokoyama, A. \& Yokozawa, T. Converting step-growth to chain-growth condensation polymerization. Macromolecules 40, 4093-4101 (2007).

18 Yokozawa, T. \& Ohta, Y. Transformation of step-growth polymerization into living chain-growth polymerization. Chemical reviews 116, 1950-1968 (2016).

19 Yokozawa, T. \& Ohta, Y. Controlled Synthesis of Conjugated Polymers in Catalyst-transfer Condensation Polymerization: Monomers and Catalysts. (2016).

20 Fu, L., Xu, M., Yu, J. \& Gutekunst, W. R. Halide-Rebound Polymerization of Twisted Amides. J Am Chem Soc 141, 2906-2910, doi:10.1021/jacs.8b13731 (2019).

21 Kosaka, K., Uchida, T., Mikami, K., Ohta, Y. \& Yokozawa, T. AmPhos Pd-Catalyzed SuzukiMiyaura Catalyst-Transfer Condensation Polymerization: Narrower Dispersity by Mixing the Catalyst and Base Prior to Polymerization. Macromolecules 51, 364-369, doi:10.1021/acs.macromol.7b01990 (2018).

22 Yokozawa, T., Kohno, H., Ohta, Y. \& Yokoyama, A. Catalyst-Transfer Suzuki-Miyaura Coupling Polymerization for Precision Synthesis of Poly(p-phenylene). Macromolecules 43, 7095-7100, doi:10.1021/ma101073x (2010).

23 Yano, Y. et al. Living annulative pi-extension polymerization for graphene nanoribbon synthesis. Nature 571, 387-392, doi:10.1038/s41586-019-1331-z (2019).

24 Kang, J. et al. A rational strategy for the realization of chain-growth supramolecular polymerization. Science 347, 646-651 (2015).

25 Qin, A., Lam, J. W. \& Tang, B. Z. Click polymerization. Chemical Society Reviews 39, 2522-2544 (2010).

26 Wu, P. et al. Efficiency and fidelity in a click-chemistry route to triazole dendrimers by the copper (I)-catalyzed ligation of azides and alkynes. Angewandte Chemie 116, 4018-4022 (2004).

27 Díaz, D. D. et al. Click chemistry in materials synthesis. 1. Adhesive polymers from coppercatalyzed azide-alkyne cycloaddition. Journal of Polymer Science Part A: Polymer Chemistry 42, 4392-4403 (2004).

28 Xi, W., Scott, T. F., Kloxin, C. J. \& Bowman, C. N. Click chemistry in materials science. Advanced Functional Materials 24, 2572-2590 (2014). 
Lee, I.-H., Kim, H. \& Choi, T.-L. Cu-catalyzed multicomponent polymerization to synthesize a library of poly (N-sulfonylamidines). Journal of the American Chemical Society 135, 3760-3763 (2013).

30 Kim, H. \& Choi, T.-L. Preparation of a library of poly (N-sulfonylimidates) by Cu-catalyzed multicomponent polymerization. ACS Macro Letters 3, 791-794 (2014).

31 Liu, X., Han, T., Lam, J. W. \& Tang, B. Z. Functional Heterochain Polymers Constructed by Alkyne Multicomponent Polymerizations. Macromolecular Rapid Communications, 2000386 (2020).

32 Kim, H., Bang, K.-T., Choi, I., Lee, J.-K. \& Choi, T.-L. Diversity-oriented polymerization: oneshot synthesis of library of graft and dendronized polymers by Cu-catalyzed multicomponent polymerization. Journal of the American Chemical Society 138, 8612-8622 (2016).

Shi, Y., Graff, R. W., Cao, X., Wang, X. \& Gao, H. Chain-growth click polymerization of AB2 monomers for the formation of hyperbranched polymers with low polydispersities in a one-pot process. Angew Chem Int Ed Engl 54, 7631-7635, doi:10.1002/anie.201502578 (2015).

Gan, W., Cao, X., Shi, Y.\& Gao, H. Chain-growth polymerization of azide-alkyne difunctional monomer: Synthesis of star polymer with linear polytriazole arms from a core. Journal of Polymer Science 58, 84-90, doi:10.1002/pola.29440 (2019).

35 Dong, J., Sharpless, K. B., Kwisnek, L., Oakdale, J. S. \& Fokin, V. V. SuFEx-Based Synthesis of Polysulfates. Angewandte Chemie International Edition 53, 9466-9470 (2014).

36 Barrow, A. et al. The growing applications of SuFEx click chemistry. Chemical Society Reviews 48, 4731-4758 (2019).

37 Gao, B. et al. Bifluoride-catalysed sulfur (VI) fluoride exchange reaction for the synthesis of polysulfates and polysulfonates. Nature chemistry 9, 1083 (2017).

38 Wang, H. et al. SuFEx-Based Polysulfonate Formation from Ethenesulfonyl Fluoride-Amine Adducts. Angewandte Chemie 129, 11355-11360 (2017).

39 Li, S. et al. SuFExable Polymers with Helical Structures Derived from Thionyl Tetrafluoride (SOF4). (2019).

40 Xu, L., Wu, P. \& Dong, J. New Polymers From SuFEx Click Chemistry: Syntheses and Perspectives. (2019).

41 Li, S., Wu, P., Moses, J. E. \& Sharpless, K. B. Multidimensional SuFEx click chemistry: sequential sulfur (VI) fluoride exchange connections of diverse modules launched from an SOF4 hub. Angewandte Chemie 129, 2949-2954 (2017).

42 Sugi, R., Yokoyama, A., Furuyama, T., Uchiyama, M. \& Yokozawa, T. Inductive Effect-Assisted Chain-Growth Polycondensation. Synthetic Development from p ara-to $m$ eta-Substituted Aromatic Polyamides with Low Polydispersities. Journal of the American Chemical Society 127, 10172-10173 (2005).

43 Ohishi, T., Sugi, R., Yokoyama, A. \& Yokozawa, T. A variety of poly (m-benzamide) s with low polydispersities from inductive effect-assisted chain-growth polycondensation. Journal of Polymer Science Part A: Polymer Chemistry 44, 4990-5003 (2006).

44 Esser-Kahn, A. P., Odom, S. A., Sottos, N. R., White, S. R. \& Moore, J. S. Triggered release from polymer capsules. Macromolecules 44, 5539-5553 (2011).

45 Li, J. \& Mooney, D. J. Designing hydrogels for controlled drug delivery. Nature Reviews Materials 1, 1-17 (2016).

46 Gillies, E. R. \& Frechet, J. M. Dendrimers and dendritic polymers in drug delivery. Drug discovery today 10, 35-43 (2005).

47 Fu, K. K., Wang, Z., Dai, J., Carter, M. \& Hu, L. Transient electronics: materials and devices. Chemistry of Materials 28, 3527-3539 (2016).

48 Cao, Z. et al. Preparation of aryl polysulfonates via a highly efficient SuFEx click reaction, their controllable degradation and functionalized behavior. Polymer Chemistry 11, 3120-3124 (2020).

49 Liu, C. et al. A General Approach to O-Sulfation by a Sulfur (VI) Fluoride Exchange Reaction. Angewandte Chemie 132, 18593-18599 (2020). 
50 Feist, J. D. \& Xia, Y. Enol Ethers Are Effective Monomers for Ring-Opening Metathesis Polymerization: Synthesis of Degradable and Depolymerizable Poly(2,3-dihydrofuran). J Am Chem Soc 142, 1186-1189, doi:10.1021/jacs.9b11834 (2020).

$51 \mathrm{Xu}, \mathrm{Y}$. et al. Base-triggered self-amplifying degradable polyurethanes with the ability to translate local stimulation to continuous long-range degradation. Chemical Science 11, 3326-3331, doi:10.1039/c9sc06582b (2020).

52 Shieh, P., Nguyen, H. V. \& Johnson, J. A. Tailored silyl ether monomers enable backbonedegradable polynorbornene-based linear, bottlebrush and star copolymers through ROMP. Nat Chem 11, 1124-1132, doi:10.1038/s41557-019-0352-4 (2019).

53 Shieh, P. et al. Cleavable comonomers enable degradable, recyclable thermoset plastics. Nature 583, 542-547, doi:10.1038/s41586-020-2495-2 (2020).

54 Amamoto, Y., Kamada, J., Otsuka, H., Takahara, A. \& Matyjaszewski, K. Repeatable photoinduced self-healing of covalently cross-linked polymers through reshuffling of trithiocarbonate units. Angewandte Chemie 123, 1698-1701 (2011).

55 Lu, Y.-X. \& Guan, Z. Olefin metathesis for effective polymer healing via dynamic exchange of strong carbon-carbon double bonds. Journal of the American Chemical Society 134, 14226-14231 (2012).

56 García, J. M. et al. Recyclable, strong thermosets and organogels via paraformaldehyde condensation with diamines. Science 344, 732-735 (2014). 